\title{
Depth-dependent molecular composition and photo-reactivity of dissolved organic matter in a boreal lake under winter and summer conditions
}

\author{
M. Gonsior ${ }^{1,2}$, P. Schmitt-Kopplin ${ }^{3,4}$, and D. Bastviken ${ }^{2}$ \\ ${ }^{1}$ University of Maryland Center for Environmental Science, Chesapeake Biological Laboratory, Solomons, MD, USA \\ ${ }^{2}$ Linköping University, Department of Thematic Studies, Unit Water and Environment, Linköping, Sweden \\ ${ }^{3}$ Helmholtz Zentrum Munich, German Research Center for Environmental Health, Neuherberg, Germany \\ ${ }^{4}$ Department for Chemical-Technical Analysis, Research Center Weihenstephan for Brewing and Food Quality, Technische \\ Universität München, 85354 Freising-Weihenstephan, Germany \\ Correspondence to: M. Gonsior (gonsior@umces.edu)
}

Received: 15 April 2013 - Published in Biogeosciences Discuss.: 29 May 2013

Revised: 23 September 2013 - Accepted: 2 October 2013 - Published: 4 November 2013

\begin{abstract}
Transformations of dissolved organic matter (DOM) in boreal lakes lead to large greenhouse gas emissions as well as substantial carbon storage in sediments. Using novel molecular characterization approaches and photochemical degradation experiments we studied how seasonal patterns in water column stratification affected the DOM in a Swedish lake under early spring and summer conditions. Dissolved organic carbon (DOC) concentrations were consistently higher above the sediment when compared to surface waters throughout the sampling periods. Photobleaching alone could not explain this difference in DOC because the lake was covered by $40 \mathrm{~cm}$-thick ice during late winter sampling and still showed the same DOC trend. The differences in the molecular diversity between surface DOM in winter and summer were consistent with ongoing photobleaching/decarboxylation and a possible bacterial consumption of photo-products. Additional photo-degradation experiments using simulated sunlight showed a production of highly oxidized organic molecules and low molecular weight compounds in all late winter samples and also in the deep water sample in summer. In the surface summer DOM sample, few such molecules were produced during the photodegradation experiments, confirming that DOM was already photobleached prior to the experiments. This study suggests that photobleaching, and therefore also the ice cover during winter, plays a central role in surface DOM transformation, with important differences in the molecular composi-
\end{abstract}

tion of DOM between surface and deep boreal lake waters. The release of DOC from boreal lake sediments also contribute to this pattern. Photochemical degradation of DOM may be more extensive following ice-out and water column turnover when non-light exposed and thereby photosensitive DOM is photo-mineralized. Hence, the yearly DOM photomineralization may be greater than inferred from studies of recently light-exposed DOM.

\section{Introduction}

It is becoming increasingly clear that processes in freshwaters play a key role for global carbon cycling and in particular for the fate of the organic matter (OM) exported from soils. Large amounts of OM are decomposed to carbon dioxide and methane in lakes and estimated emissions of these gases correspond to $79 \%$ of the continental uptake of carbon dioxide equivalents (Bastviken et al., 2011). At the same time OM can also flocculate, sink, and become buried and preserved in sediments (von Wachenfeldt and Tranvik, 2008; Sobek et al., 2012). Recent estimates are that sediments harbor $98 \%$ of the boreal lake OM (Einola et al., 2011), and that the yearly sedimentary burial of $\mathrm{OM}$ in lakes exceed the burial in the oceans (Tranvik et al., 2009). The remainder will be transported downstream towards the ocean. The processes behind these different fates are driven by interactions between the 
quantity and quality of the $\mathrm{OM}$, microbial metabolism, and abiotic processes such as photochemistry and the balance between flocculation and dissolution of OM. However, the relative magnitude and the regulation of OM fates are still unclear in most systems.

There have been numerous short-term incubation studies of microbial and photochemical interactions with dissolved OM (DOM) degradation in lake waters (Moran and Zepp, 1997). It has been shown that the combination of initial photochemical degradation of the DOM form smaller molecules and that they are more accessible to microbial degradation. This is also important for the total OM mineralization (Bertilsson and Allard, 1996; Tranvik and Bertilsson, 2001; Anesio et al., 2005). When expanding these findings from short-term incubations over time and space, large seasonal differences in lake OM cycling should be expected in stratified and ice-covered systems where different proportions of the $\mathrm{OM}$ are exposed to light during different seasons. Given that $51 \%$ of the global lake area is situated north of $48^{\circ}$ latitude (Downing and Duarte, 2009), and that these lakes are chromophoric DOM (CDOM) rich, such seasonal effects could actually be a major determinant of the fates of OM in lakes. It is well established that during summer stratification in dimictic lakes, the CDOM levels in the surface layer (epilimnion) is decreased due to photobleaching when compared to the deeper waters below the thermocline (hypolimnion) (Bracchini et al., 2006). As a result, photobleaching is a significant and major player in molecular alteration of DOM (Moran et al., 2000; Stubbins et al., 2012; Zhang et al., 2006). Modeling attempts stressed that $50 \%$ of the CDOM light absorption within the entire water column in lakes can be lost in 18-44 days under summer conditions due to photobleaching (Reche et al., 2000). However this model did not take into account that different CDOM components are likely to degrade at different timescales. For example, it is likely that at the onset of sunlight exposure a preferential loss of highly photosensitive components of (C)DOM occurs and that slower photo-degrading DOM constituents are relatively increased but continue to photo-degrade at slower rates.

Seasonal stratification and the change in redox conditions may also be important for a relatively neglected process in lake carbon cycling studies - re-dissolution of particulate OM from lake sediments (Skoog and Arias-Esquivel, 2009; Cottrell et al., 2013). During stratification periods, nearbottom water layers often become anoxic, which affect all redox-sensitive equilibria (Skoog and Arias-Esquivel, 2009) and processes, as well as e.g. $\mathrm{pH}$, and this could affect $\mathrm{OM}$ solubility and availability (Phelps and Zeikus, 1984). The redissolution can be important for assessments of OM stability, and burial in lake sediments.

We addressed the hypotheses that seasonal patterns in water column stratification are important for lake carbon cycling by constraining photo-degradation and by inducing bottom water conditions that enhance the re-dissolution of sedimented particulate OM. To do this, we assessed how the quality and characteristics of OM changed between winter and summer conditions and within the water column, both in situ and after a series of photochemical experiments, using measurements of optical properties such as ultraviolet/visible (UV/Vis) spectroscopy and excitation emission matrix (EEM) fluorescence spectroscopy combined with ultrahigh-resolution electrospray ionization Fourier Transform Ion Cyclotron Resonance Mass Spectrometry (FT-MS).

\section{Methods}

\subsection{Sampling}

In the sample collection for the core analyses of this study, one-liter water samples were collected at $0.5 \mathrm{~m}$ depth (surface), and just above the sediment at $7 \mathrm{~m}$ depth in April and June 2011 in Lillsjön (58 39 $\left.33.05^{\prime \prime} \mathrm{N}, 16^{\circ} 8^{\prime} 34.81^{\prime \prime} \mathrm{E}\right)$, a lake located in Östergötland, Sweden. During the first sampling in April, the lake was still covered by $40 \mathrm{~cm}$-thick ice that started to form in November 2010. Dissolved oxygen and temperature profiles were measured during sampling using a hand-held probe (Hach HQ40d).

Additional water column profile data on temperatures and DOC was collected as above and the same location (same lake and same sampling area) in August 1999 and March 2000 (under ice), and analyzed immediately for dissolved organic carbon (DOC) as described below. These older DOC profiles were used as independent supplementary data when discussing the potential for DOC release from sediments.

All water samples were directly filtered through Whatman $\mathrm{GF} / \mathrm{F}$ glassfiber filters and acidified after filtration to pH 2 using ultrapure concentrated $\mathrm{HCl}$ (Sigma Aldrich 32\%, puriss. p.a.). Overall, $800 \mathrm{~mL}$ of each water sample was then solid-phase extracted (SPE) as described elsewhere (Dittmar et al., 2008). Briefly, Agilent Bond Elut PPL solid-phase extraction cartridges, filled with $1 \mathrm{~g}$ of the PPL resin (a styrene-divinylbenzene polymer that has been modified with a proprietary non-polar surface), were pre-conditioned with methanol, rinsed with acidified ( $\mathrm{pH}$ 2) Milli-Q water and then the water sample was gravity-fed through it. DOC was measured on acidified samples before and after the SPE extraction using a Shimadzu 5000 TOC analyzer and carbon adsorption efficiencies ranged between 58 and $64 \%$, and were very similar to literature values of a variety of DOM samples (Dittmar et al., 2008; Gonsior et al., 2011; Shakeri Yekta et al., 2012). The absorbance of the samples before and after SPE extraction was also measured using an Ultraspec 2100 Pro (scan over 190-700 nm) and showed an average recovery of the CDOM of $63 \%$. The SPE extracts were eluted with methanol and stored at $-20^{\circ} \mathrm{C}$ in a freezer prior to photochemical experiments. Neither the shape of the absorbance nor the fluorescence signals of the SPE extract changed noticeably. 


\subsection{Photochemical experiments}

After completely drying of $1 \mathrm{~mL}$ of each SPE-DOM sample under nitrogen gas and the re-dissolution in $40 \mathrm{~mL}$ high purity water (LC-MS grade water, Chromasolv, SigmaAldrich), the sample $\mathrm{pH}$ was close to the original water sample at $\mathrm{pH}$ 6.5. This was important to avoid changes in the $\mathrm{pH}$-dependent shift in absorbance and photobleaching as described elsewhere (Pace et al., 2012; Janot et al., 2010).

The samples were then divided and half of the sample $(20 \mathrm{~mL})$ was continuously pumped through a custom-built photo reactor cell made out of Tefzel tubing for $24 \mathrm{~h}$. A $10 \mathrm{~mL}$ gas equilibrator was also attached in-line to allow saturation of air gases at any given time. The flat-coiled cell was exposed to simulated sunlight (SolSim Luzchem) that closely matched the intensity of one sun at a solar zenith angle of $z=48.2^{\circ}$ (1.5 AirMass filter) corresponding to temperate latitudes and an intensity of $870 \mathrm{~W} \mathrm{~m}^{-2}$. The Tefzel polymer (ethylene tetrafluoroethylene) has excellent lighttransmitting properties with $>90 \%$ at $300 \mathrm{~nm}$. This system has several advantages, including minimizing inner filtering effects (due to the very short path length of $1 \mathrm{~mm}$ ), avoiding starvation of air gases (gas equilibrator) and being a closed system avoiding contamination during extended sunlight exposure times.

Dark controls were stored in the dark at similar temperature maintained within the ventilated solar simulator chamber. All samples (irradiated and dark controls) were diluted with $50 \%$ LC-MS methanol and analyzed by negative mode electrospray FT-MS. The differences between the dark controls and the irradiated samples were used to evaluate the photo-degradation at the molecular level.

\subsection{Measurements of optical properties}

Absorbance measurements were undertaken on all samples before and after exposure to simulated sunlight using a Cary Bio100 Spectrophotometer with $1 \mathrm{~cm}$ quartz cuvettes. The spectral slopes and slope ratios were calculated using a firstorder decay function at the wavelengths ranges $275-295 \mathrm{~nm}$ and $350-400 \mathrm{~nm}$ and according to a detailed description previously published (Helms et al., 2008). Excitation emission matrix (EEM) fluorescence spectra were recorded using a Horiba Fluoromax 4 Spectrofluorometer at $5 \mathrm{~nm}$ excitation intervals between $240-500 \mathrm{~nm}$ and an emission range of $290-600 \mathrm{~nm}$ at $2 \mathrm{~nm}$ intervals. Scatter-correction and normalization to quinine sulfate equivalency was performed similar to the procedure described elsewhere (Zepp et al., 2004). All samples were diluted $1: 10$ prior to all optical property analyses to avoid inner-filtering effects, and to be able to apply the linear range of the quinine sulfate calibration of the EEM spectra.

\subsection{Ultrahigh-resolution mass spectrometric analysis}

A Bruker Apex QE 12 Tesla FT-MS with negative mode electrospray ionization located at the Helmholtz Center for Environmental Health, Munich, Germany was used to analyze the SPE-DOM samples from the lake after a dilution of $1: 100$ and all samples before and after photochemical degradation experiments at similar dilution. Electrospray is a soft ionization technique that creates largely intact molecules (no fragmentation) with a single charge and the ultrahigh resolution (mass error $<0.2 \mathrm{ppm}$ and mass resolution $>400000$ at mass 400) allows for the unambiguous assignment of molecular formulae from all $\mathrm{m} / \mathrm{z}$ peaks (Stenson et al., 2003). The accuracy of the used FT-MS is high enough to distinguish masses with a difference of less than an electron and hence multiply charged ions can be distinguished and are rarely observed due to their much weaker ionization efficiencies when compared to their singly charged counterparts. The following chemical elements were allowed to calculate molecular formulae: ${ }^{12} \mathrm{C}_{0-\infty},{ }^{1} \mathrm{H}_{0-\infty},{ }^{16} \mathrm{O}_{0-\infty},{ }^{14} \mathrm{~N}_{0-5}$ and ${ }^{32} \mathrm{~S}_{0-2}$ as well as the ${ }^{13} \mathrm{C}_{0-1}$ carbon isotope. Unambiguous molecular formula assignments are now possible up to 800 Dalton due to the mass accuracy of less than $0.2 \mathrm{ppm}$. Further information on how to accurately assign molecular formulae to ultrahigh-resolution FT-MS data is given elsewhere (Dittmar et al., 2007; Schmitt-Kopplin and Hertkorn, 2007). Briefly, the mass spectra were calibrated across the observed mass range $(150-700 \mathrm{Da})$ using internal standards of high relative abundance exact mass peaks with known molecular formulas that have been previously found in all DOM samples. External pre-calibration was undertaken using arginine standards prior to mass spectrometric analyses. The reproducibility of the SPE method in conjunction with the same mass spectrometer used in this study has been previously described on triplicate samples (Shakeri Yekta et al., 2012). The reproducibility of the relative abundances of mass peaks was good and showed on average less than $4 \%$ variability, but maximum differences of $10 \%$ of high abundance mass peaks may occur; hence we only considered changes in relative abundance that exceeded $10 \%$ relative difference. Usually 20 $30 \%$ of the mass peaks have low enough intensity to be either above or below the set signal to noise ratio in replicate samples. This can cause a large variability between replicates for such low intensity mass peaks (Shakeri Yekta et al., 2012). Correspondingly, an analysis to find unique mass peaks in each sample revealed that unique mass peaks showed always very low abundances, indicating that they were likely not unique but just had an intensity above the signal to noise ratio in some samples. To avoid any artifacts of the data, we only considered mass peaks that were commonly found in all samples of the same treatment. Van Krevelen diagrams where the elemental ratios of oxygen to carbon $(\mathrm{O} / \mathrm{C})$ are plotted against the hydrogen to carbon $(\mathrm{H} / \mathrm{C})$ ratios of each individually assigned molecular formula are particularly useful for visualizing FT-MS data and showing the chemical space of a 
DOM sample occupied in this specific elemental plot (Kim et al., 2003) and were used throughout the study.

Another useful visualization tool is the Kendrick diagram, where the Kendrick mass defect (KMD) is plotted against the nominal mass (Kendrick, 1963; Wu et al., 2004). The Kendrick mass (KM) is essentially a normalization of the International Union of Pure and Applied Chemistry (IUPAC) mass to the mass of $\mathrm{CH}_{2}$ groups $(m=14.01565)$ and the KMD is the difference between nominal mass (NM) and KM.

$\mathrm{KM}=\mathrm{IUPAC}$ mass $\times(14.000000 / 14.01565)$

$\mathrm{KMD}=\mathrm{NM}-\mathrm{KM}$

All homologues of $\mathrm{CH}_{2}$ would have the same KMD and therefore it can be used to distinguish $\mathrm{CH}_{2}$ homologues common in FT-MS data of DOM. A second independent parameter $\left(z^{*}\right)$ was used to assign homologues as

$z^{*}=(\bmod [\mathrm{NM} / 14])-14$

The modulus (mod) function returns the remainder after the NM is divided by 14 (Stenson et al., 2003). Here, we used a modified Kendrick plot where the ratio of the KMD is divided by $z^{*}$ and then plotted against the mass to show accurately unambiguous homologous series in one plot (Shakeri Yekta et al., 2012).

\section{Results and discussion}

During the April sampling, the dissolved oxygen saturation was $59 \%$ just underneath the ice and decreased rapidly with depth to low oxygen levels (1\%) at $0.5 \mathrm{~m}$ above the sediment (Fig. 1). However, the bottom water had probably been oxic until just before the sampling, as indicated by previous oxic profiles taken in the month of March (data not shown).

In June, the lake was strongly stratified with $100 \%$ oxygen saturation at $0.5 \mathrm{~m}$ depth, decreasing with depth to about $18 \%$ at $0.5 \mathrm{~m}$ above sediment (Table 1 and Fig. 1). At both sampling periods, the DOC concentrations were consistently higher $0.5 \mathrm{~m}$ above sediment than at $0.5 \mathrm{~m}$ below the surface. The DOC concentration was highest in the deep sample under ice followed by surface sample under ice, deep sample in summer and surface sample in summer (Table 1). This indicated either a source of DOM to the bottom water and/or a DOC dilution/depletion at the surface both under ice and during summer. Under the winter conditions with the existing ice cover and frozen soils, it seemed unlikely that the surface water was diluted (rain, runoff etc.). The most likely reason for the higher DOM concentrations in the bottom water is release from sediment. A change in the redox potential at the sediment surface caused by switching from aerobic to anaerobic conditions has previously been reported to cause a

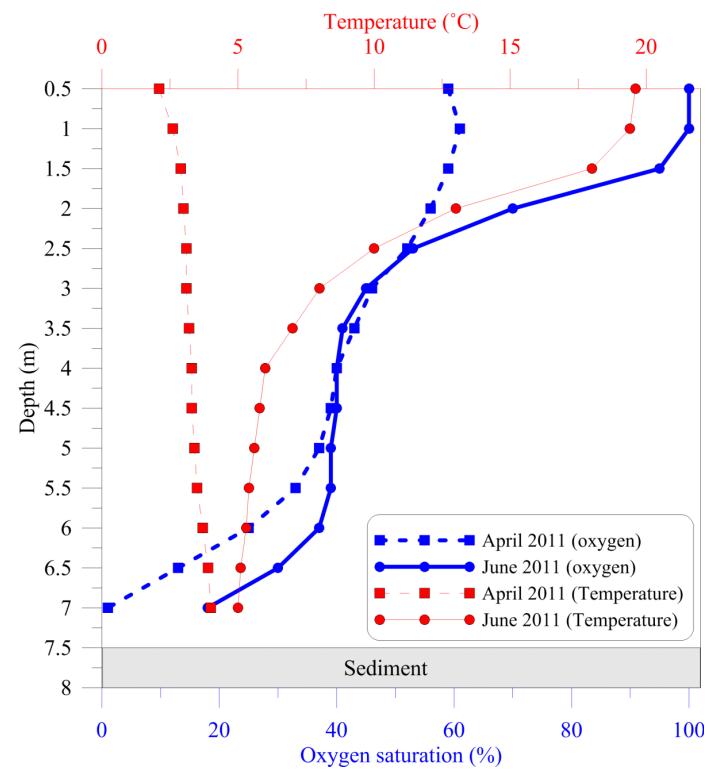

Fig. 1. Temperature and dissolved oxygen saturation profiles of Lillsjön Lake in April and June 2011.

high release of DOC at the onset of anoxia (Skoog and AriasEsquivel, 2009). In our case, this may have occurred in the month before the April sampling. Another alternative explanation could be higher microbial mineralization in the surface water, but it is difficult to find good arguments for this, given the slightly lower winter temperatures in the surface water and that most parts of the hypolimnion were oxic during the winter. The strongest support of DOM release from the sediments are derived from DOC distribution under ice when the temperature profile (and the microbial degradation) and the light influence throughout the water column is more uniform than during summer. The more detailed DOC profiles from August 1999 and March 2000 (under ice) support the findings from 2011 and indicate considerable DOC release from sediments under ice (Fig. 2).

In June the bottom water DOC levels were close to (slightly lower than) surface levels in April. This is logical given the combination of (1) lake circulation mixing the larger surface water volume with a smaller bottom water volume, (2) increased temperatures and thereby increased DOC mineralization throughout the water column, and (3) some photo-mineralization during the circulation period affecting the whole water column. After lake circulation, the surface water DOC levels was likely reduced further by additional photo-mineralization and enhanced microbial degradation as temperatures increased further. Additional DOM sources that may have influenced the DOC concentrations between April and June cannot be ruled out but the months of April, May and June 2011 were particularly dry in this region and large amounts of leaching from forest soils after spring mixing was unlikely. Photochemical experiments were undertaken to evaluate if differences existed between 
Table 1. Temperature, dissolved oxygen and DOC concentrations during sampling of Lillsjön, a boreal lake in 2011.

\begin{tabular}{ll|ccc|ccc}
\hline & & Sampling & $04 / 01 / 2011$ & & Sampling & $06 / 28 / 2011$ \\
\hline Sample Lillsjön & Depth $(\mathrm{m})$ & $T\left({ }^{\circ} \mathrm{C}\right)$ & $\mathrm{O}(\%)$ & $\mathrm{DOC}\left(\mathrm{mg} \mathrm{L}^{-1}\right)$ & $T\left({ }^{\circ} \mathrm{C}\right)$ & $\mathrm{O}(\%)$ & $\mathrm{DOC}\left(\mathrm{mg} \mathrm{L}^{-1}\right)$ \\
\hline \multirow{2}{*}{ surface } & 0.5 & 2.1 & 59 & $22.7 \pm 0.3$ & 19.4 & 100 & $18.7 \pm 0.2$ \\
bottom & 7 & 4 & 1 & $25.0 \pm 0.2$ & 4.7 & 18 & $21.5 \pm 0.2$ \\
\hline
\end{tabular}

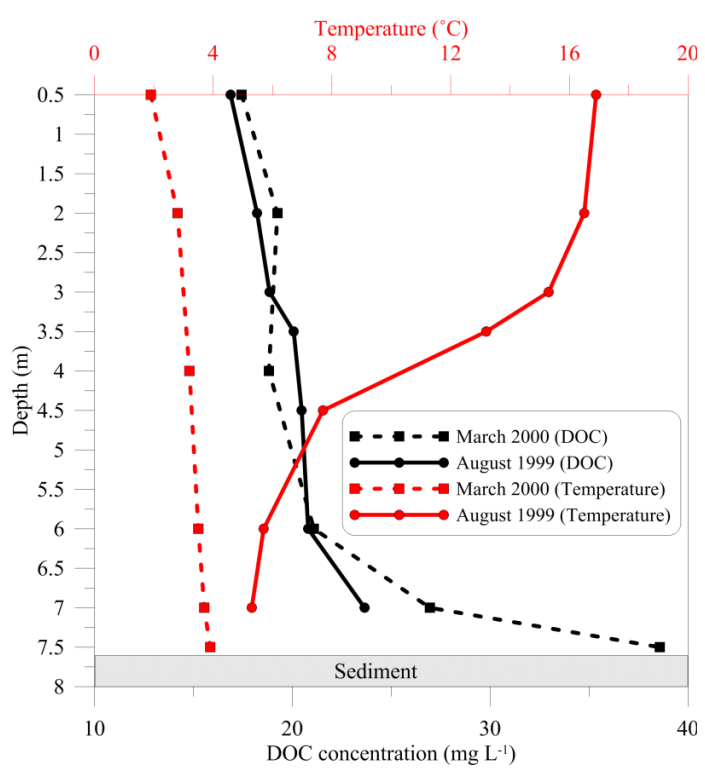

Fig. 2. Depth profiles of DOC and temperature in Lillsjön Lake in 24 August 1999 (summer) and 7 March 2000 (winter).

the photochemical reactivity (photobleaching) of DOM between surface and deep water as a function of season and a comparison between ice-covered and light-protected surface waters in early spring, with strongly exposed surface water in summer after exposure to sunlight during the dry and sunny spring of 2011. If a release of DOM from sediments occurred and the significant differences in DOC concentrations between surface and deep waters are not primarily related to photobleaching, then there should not be a great difference between photobleaching in surface and deep waters under winter conditions and during ice-cover. Indeed photochemical degradation of solid-phase extracted DOM (SPE-DOM) and its associated changes in optical properties in April at the surface and just above the sediment after the exposure to $24 \mathrm{~h}$ simulated sunlight was substantial but revealed only small changes between depths (Figs. 3 and 4). The spectral slope ratios $\left(S_{\mathrm{r}}\right)$, obtained by dividing the slope calculated between 275-295 $\mathrm{nm}$ and 350-400 nm (Helms et al., 2008), showed also significant changes towards higher values after irradiation time, but was relatively similar between depths (18\% increase in the April surface and $20 \%$ in the April bottom water sample) (Table 2). In general, these results are in agreement with the Helms et al. study and would suggest a decrease in molecular weight after irradiation. In contrast, the same photochemical experiments undertaken on water sampled in June showed much less photobleaching at the surface when compared to deep water SPE-DOM (Figs. 3 and 4). The photochemically induced changes in $S_{\mathrm{r}}$ also confirmed this trend with an increase of only $14 \%$ in the June surface sample compared to $22 \%$ in the bottom water sample (Table 2). This indicates that a significant amount of the surface CDOM had already been photobleached by natural sunlight prior to additional laboratory-based photobleaching experiments. An alternative explanation would be a microbial degradation of CDOM during spring and the much warmer surface water. However, this was shown to be a rather slow process and a decrease in fluorescent intensity of up to $40 \%$ in $3.5 \mathrm{yr}$ has been demonstrated (Kothawala et al., 2012). Another study suggested the involvement of lake bacterial communities to produce and degrade CDOM, but this observation was associated with increased protein-like fluorescence arising from bacterioplankton biomass (Guillemette and del Giorgio, 2012). In this study we did not see any change in the protein-like fluorescence between winter and summer. Therefore, the involvement of bacteria in the degradation of CDOM in the June surface water sample was probably not significant when compared to photochemical degradation.

It seemed likely that the observed consistent differences between surface and deep water DOC concentrations are caused by a combination of DOC released from sediments and photobleaching/microbial degradation of DOM at the surface in summer and mainly driven by DOM fluxes from sediments in winter.

The ultrahigh-resolution, negative electrospray ionization Fourier transform, ion cyclotron resonance mass spectrometry (FT-MS) was used (Fig. 5) to allow for unambiguous assignments of molecular formulae to each exact mass peak in each sample. Only masses containing $\mathrm{C}, \mathrm{H}$ and $\mathrm{O}$ atoms were used in further analysis because nitrogen- and sulfurcontaining molecular formulas were assigned but showed low abundances in negative electrospray mass spectrometry (Fig. 5).

The comparison between surface and deep SPE-DOM under winter conditions collected in April 2011 showed that the relative abundance of highly oxidized organic compounds ( $\mathrm{O} / \mathrm{C}$ ratio between $0.50-0.87$ ) was slightly decreased in the surface compared to deep SPE-DOM, whereas the lower oxidized $(\mathrm{O} / \mathrm{C}$ ratio $<0.45)$ organic compounds showed a small 
Table 2. UV-Vis spectral slopes at distinct wavelength ranges and the resulting spectral slope ratios $\left(S_{\mathrm{r}}\right)$ of surface and deep boreal lake water samples collected in April and June 2011.

\begin{tabular}{l|llll|llll}
\hline & Sampling & $04 / 01 / 2011$ & & & Sampling & \multicolumn{2}{l}{$06 / 28 / 2011$} \\
\hline Sample Lillsjön lake & $S$ & $S_{275-395}$ & $S_{350-400}$ & $S_{\mathrm{r}}$ & $S$ & $S_{275-395}$ & $S_{350-400}$ & $S_{\mathrm{r}}$ \\
\hline surface, before irradiation & 0.0144 & 0.0135 & 0.0185 & 0.73 & 0.0145 & 0.0139 & 0.0182 & 0.76 \\
surface, after irradiation & 0.0151 & 0.0157 & 0.0176 & 0.89 & 0.0151 & 0.0158 & 0.0177 & 0.89 \\
bottom, before irradiation & 0.0143 & 0.0135 & 0.0183 & 0.74 & 0.0141 & 0.0133 & 0.018 & 0.74 \\
bottom, after irradiation & 0.0147 & 0.0159 & 0.0172 & 0.92 & 0.0144 & 0.0159 & 0.0167 & 0.95 \\
\hline
\end{tabular}
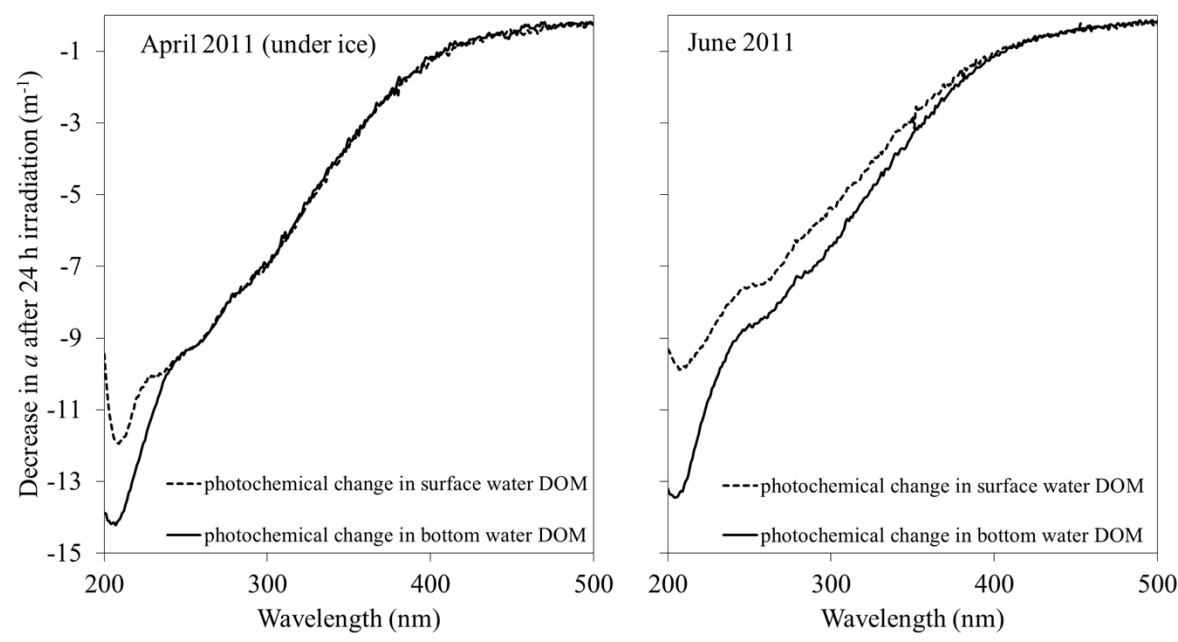

Fig. 3. Depth-dependent seasonal changes in the photochemical degradation patterns after $24 \mathrm{~h}$ exposure to simulated sunlight of lake SPEDOM and analyzed by UV/Vis absorption spectroscopy.

increase in the surface relative to deep SPE-DOM (Fig. 6). One explanation could be that more oxidized DOM is often also more water soluble (because the electronegativity of oxygen will introduce a polarization of covalent bonds and increase the overall solubility) and therefore is preferentially released from sediments. This would increase the relative abundance of more oxidized DOM in the bottom water.

In June 2011, differences between surface and deep water were primarily associated with increased abundances of mass peaks assigned to relatively low $\mathrm{H} / \mathrm{C}$ and high $\mathrm{O} / \mathrm{C}$ ratio lower molecular weight compounds in the surface SPEDOM sample (Fig. 6). Interestingly, those highly oxidized molecular formulas appeared in even higher relative abundances after light treatment in our photochemical degradation experiments (Figs. 7 and 8). Such highly oxidized formulas produced after solar simulated irradiation have been previously shown and confirmed our observation (Gonsior et al., 2009). This indicates that these molecules were photochemical products that are labile and depleted by either microbial degradation or additional photochemical decarboxylation (Xie et al., 2004; Xu and Wan, 2000) and the release of carbon mono- and dioxide and other small carboxylic acids (Bertilsson and Tranvik, 1998). Microbial respiration, whereby DOC is oxidized and dissolved inorganic carbon is formed, seemed to be an effective pathway based on dark incubation of water collected in the same lake in a previous study and the loss of about $7 \%$ of the initial DOC within 5 months at $15^{\circ} \mathrm{C}$ (Bastviken et al., 2004). To provide a crude estimate of relative contribution of microbial versus lightdependent removal of DOC in surface water between April and June in our study we assumed that the total respiration found in this previous study over 5 months $\left(1.7 \mathrm{mg} \mathrm{C} \mathrm{L}^{-1}\right)$ represented the contribution of the light-independent microbial DOC mineralization from April to June (2 months). We also assumed negligible input of water and DOC from land given the very dry conditions this spring. Then, given a total difference of $2.8 \mathrm{mg} \mathrm{DOC} \mathrm{L}^{-1}$ between surface and bottom water in June (Table 1), at least $1.1 \mathrm{mg} \mathrm{L}^{-1}$ or $40 \%$ of this relative DOC loss in the surface water should be directly or indirectly related to photochemical DOC degradation. This calculation likely overestimates the light-independent microbial contribution by using a 5-month value for 2 months, thereby underestimating the influence of photochemistry, and should not be taken literally. Rather it illustrates similar magnitudes of light-independent and photochemically induced DOC mineralization processes in lake surface water. 


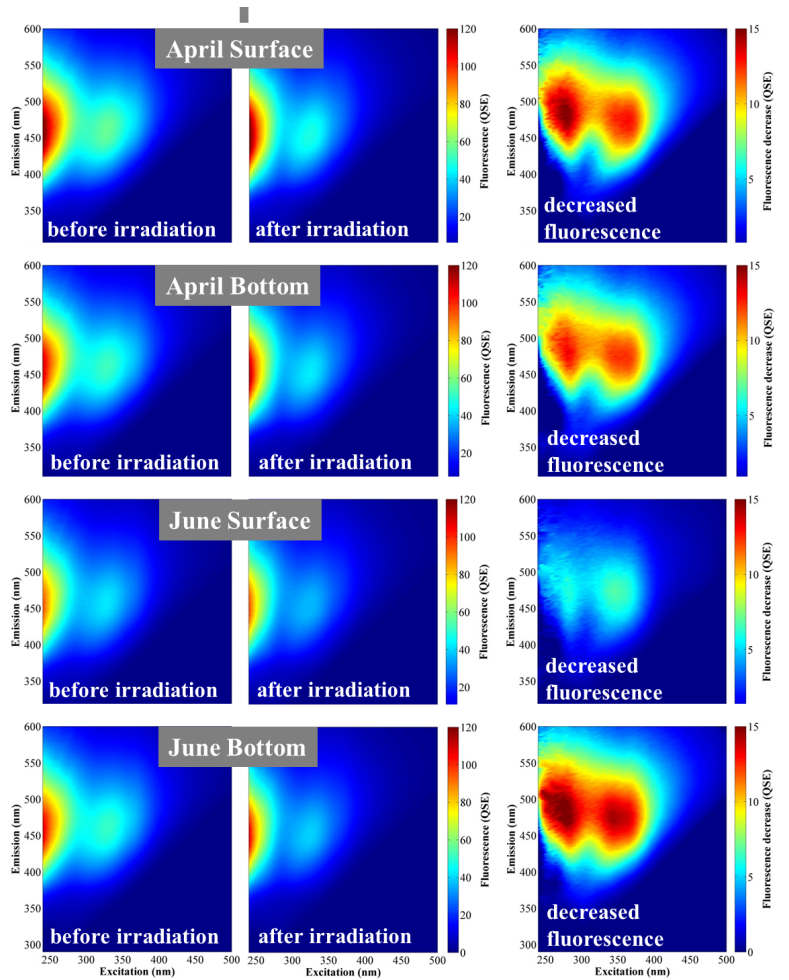

Fig. 4. Excitation emission matrix fluorescence of surface and deep SPE-DOM collected in April and June 2011 before and after exposure to simulated sunlight including a differential plot of the decreased fluorescence after irradiation. Note: SPE-DOM was dried and then re-dissolved in pure water at $\mathrm{pH} 6.5$.

The absolute decrease in absorption coefficients (Fig. 3) after $24 \mathrm{~h}$ simulated sunlight exposure was significant in all samples including the late winter and summer surface and deep samples. The photobleaching under winter conditions between surface and deep water CDOM was very similar with the only detectable differences below $240 \mathrm{~nm}$. This stands in contrast to the comparison between surface and deep CDOM in summer, where the surface CDOM is much less photobleached in the whole ultraviolet (UV) range (200$400 \mathrm{~nm})$ (Fig. 3).

The measurements of EEM spectra before and after the same irradiation time showed that the photochemically induced changes were reflected in areas in the EEM spectra that are centered around two maxima with excitation, emission couples of $280-380 \mathrm{~nm}$ and $340-375 \mathrm{~nm}$ (Fig. 4). This preferential photo-degradation of FDOM at longer wavelengths indicated a shift towards lower wavelengths of the remaining fluorescent peaks after irradiation similar to findings reported previously (Helms et al., 2013). The summer surface sample was the only sample that showed clear differences in photochemically induced degradation of fluorescent DOM (FDOM) between surface and bottom water, confirming the same trend shown in the absorbance data (Fig. 3). These re-

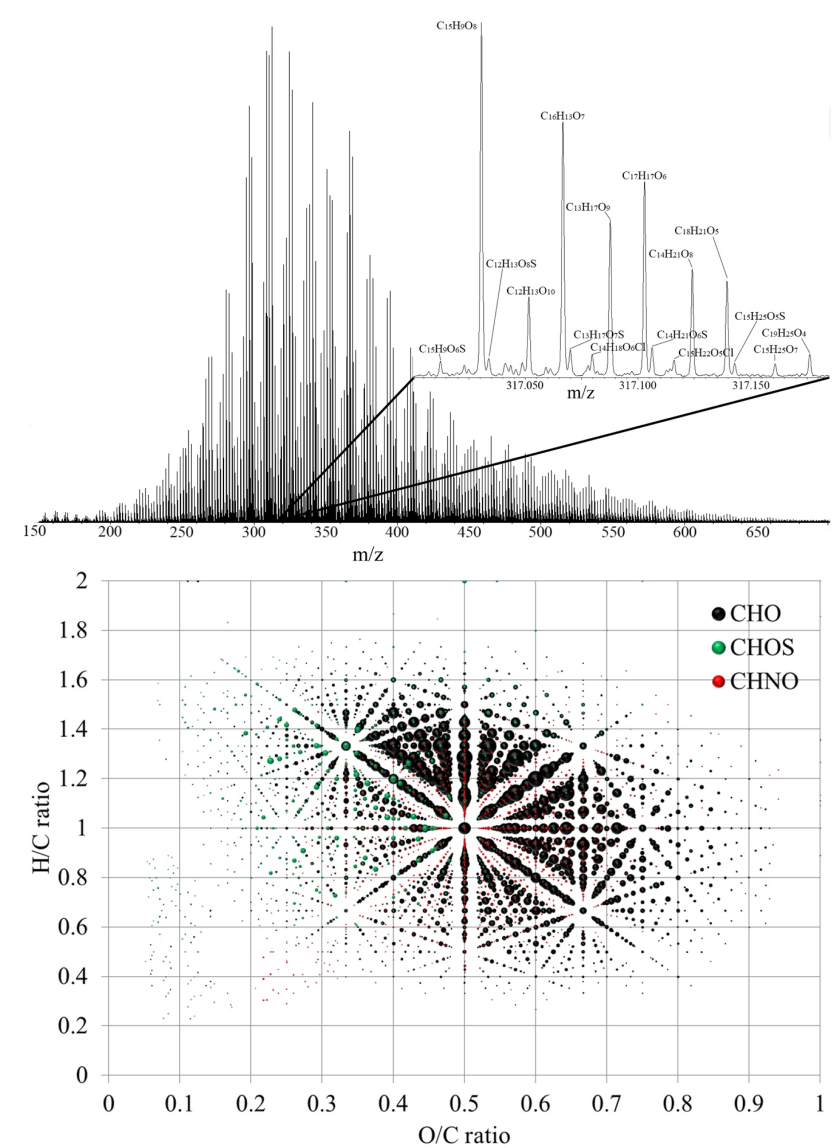

Fig. 5. Ultrahigh-resolution mass spectrum of SPE-DOM extracted from a boreal lake at the surface in April 2011 in Sweden (Lillsjön) and the van Krevelen diagram of $\mathrm{CHO}, \mathrm{CHOS}$ and $\mathrm{CHNO}$ formulae. Note: size of bubbles represent relative abundances of associated mass peaks.

sults imply that water that had not been exposed to light for extended periods (under ice or near the bottom during summer stratification) was much more photo-reactive.

This reduced photobleaching measured by optical properties (Figs. 3 and 4) of the June 2011 SPE-DOM sample already indicated that photo-active components in this SPEDOM were largely degraded prior to photobleaching experiments. As a result, the photobleaching demonstrated by changes in optical properties should be also reflected in the ultrahigh-resolution mass spectrometric data and a different photobleaching behavior in the June surface DOM sample was expected given the reduced photobleaching in this sample when compared to all others. Indeed, the surface and deep SPE-DOM sample collected in April 2011 together with the deep sample from June 2011 showed a similar photochemical behavior with a production of highly oxidized and high $\mathrm{O} / \mathrm{C}$ ratio molecules (Figs. 7 and 8). Additionally, a shift to lower molecular weight and a significant increase in relative abundance of these low molecular weight mass peaks 

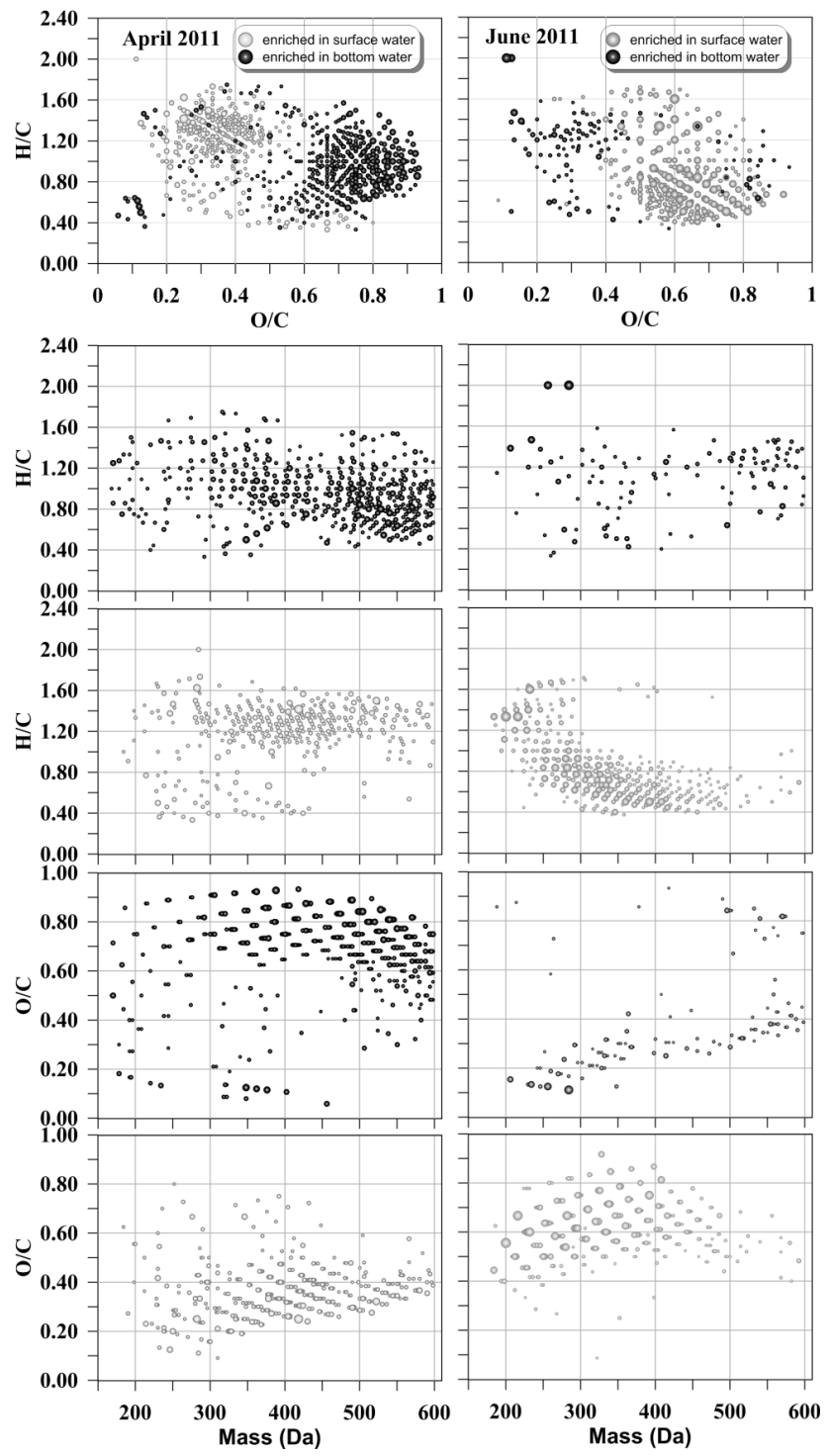

Fig. 6. Van Krevelen, $\mathrm{H} / \mathrm{C}$ and $\mathrm{O} / \mathrm{C}$ versus mass diagrams of relative differences in mass peak abundances between surface and deep SPE-DOM in April and June 2011. Note: the bubbles represent the relative abundances greater than $10 \%$.

was observed in all those samples. This trend is in agreement with previous studies where ultrafiltered DOM was photo-degraded and analyzed by size exclusion chromatography (Lou and Xie, 2006; Thomson et al., 2004). Whole water samples were also previously analyzed using optical properties (Helms et al., 2008) and ultrahigh-resolution mass spectrometry of Congo River water (Stubbins et al., 2010) with again similar findings.

The photo production of highly oxidized compounds can be explained with reaction of reactive oxygen species, such as the hydroxyl radical $(\mathrm{OH})$, super oxide $\left(\mathrm{O}_{2}^{-}\right)$and hydrogen peroxide $\left(\mathrm{H}_{2} \mathrm{O}_{2}\right)$. A photochemically induced depolymerization and a decrease in molecular weight of DOM have also
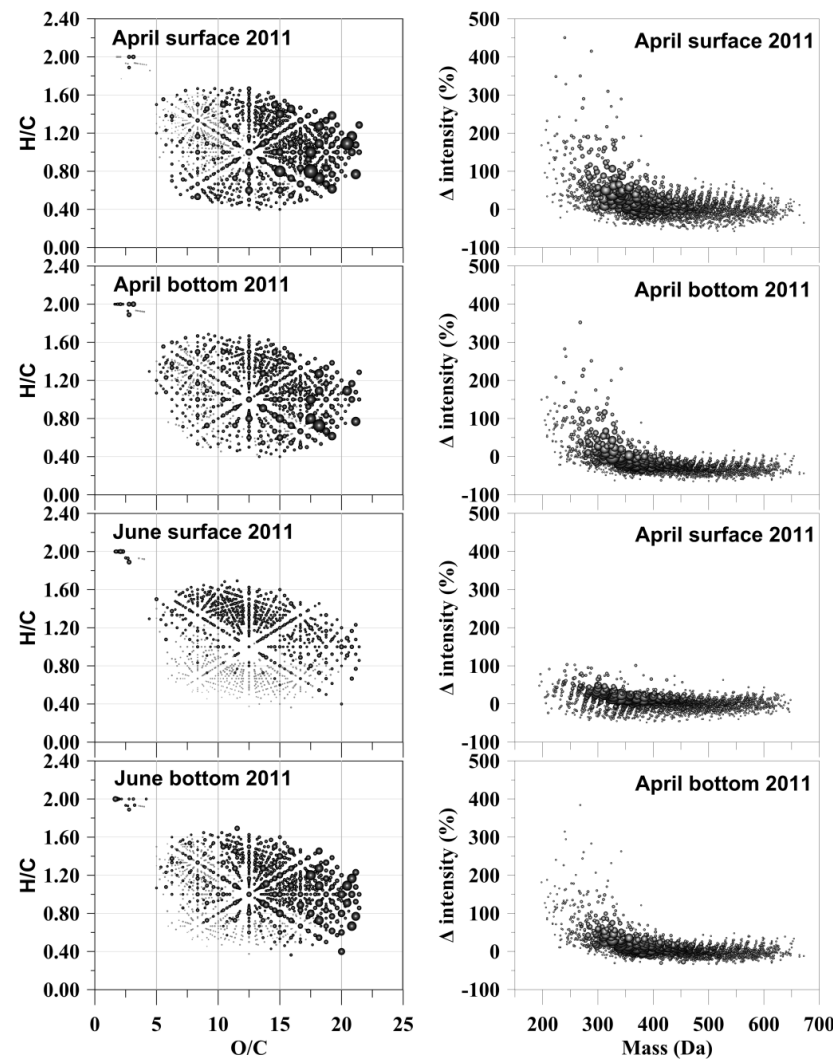

Fig. 7. Photochemically induced changes in the molecular composition of a boreal lake SPE-DOM at the surface and bottom in spring (ice covered) and at the surface and bottom in summer shown in van Krevelen diagrams and the observed relative changes in intensity for all mass peaks, respectively. (Note: black bubbles represent molecular formulas with an increase in associated relative abundances of the mass peaks after $24 \mathrm{~h}$ solar simulated irradiation and open bubbles with a decrease, respectively.)

been suggested previously (Thomson et al., 2004). The consistent decrease in all samples of mass peaks associated with $\mathrm{H} / \mathrm{C}$ ratios below 0.8 of associated molecular formulae and throughout a broad range of $\mathrm{O} / \mathrm{C}$ ratios as demonstrated with the June samples (Fig. 8, black circles), is indicative for a large pool of presumably aromatic CDOM components that are photosensitive (Table 3). The high double bond equivalency (DBE, number of double bonds and rings) and the DBE divided by the carbon number (DBE/C) values are indicative of reduced compounds (Table 3). A set of photosensitive aromatic compounds in the Cape Fear River estuary has been previously shown using FT-ICR-MS (Gonsior et al., 2009) and long-term exposure to simulated sunlight (57 days) of Congo River water also confirmed the preferential photo-degradation of the aromatic DOM content (Stubbins et al., 2010). The loss of aromatics is also in agreement with the observed photochemically induced changes in the optical properties and the decrease in conjugated aromatic 

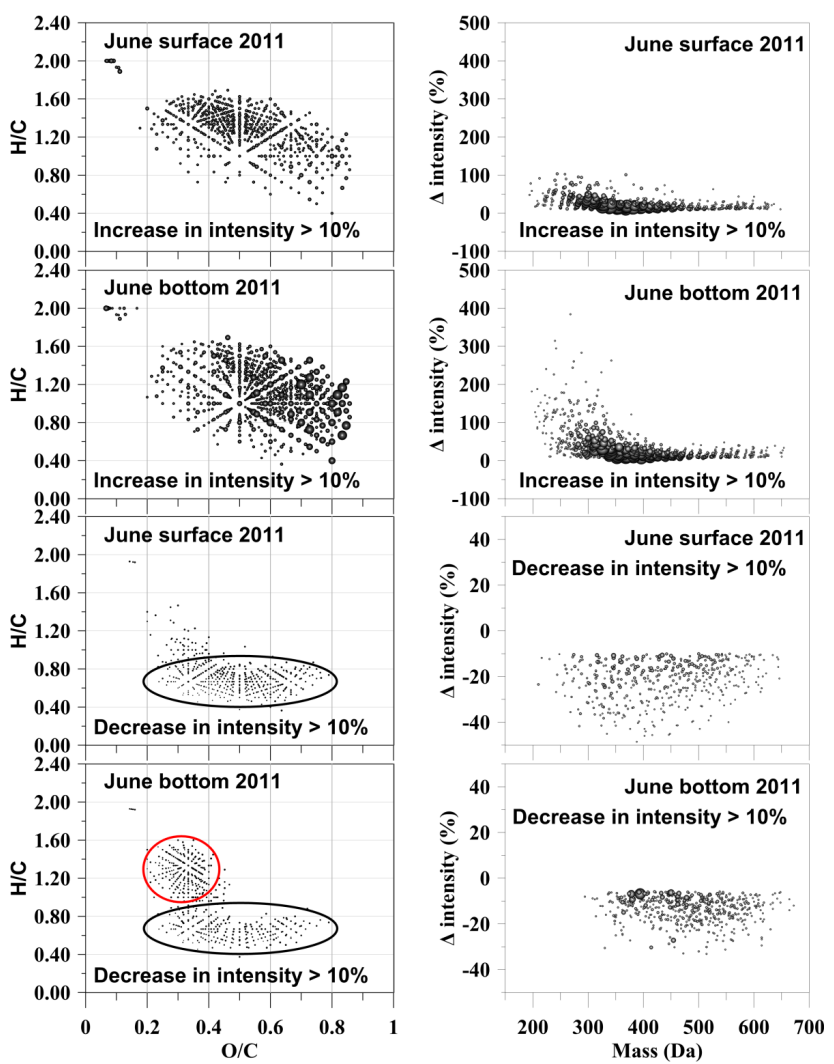

Fig. 8. Photochemically induced changes in the molecular composition of a boreal lake SPE-DOM at the surface and bottom in summer and its associated increase in intensity of mass peaks that showed more than $10 \%$ change and a decrease of more than $10 \%$, respectively. Results are illustrated using van Krevelen diagrams and diagrams where the relative change in intensity is plotted against mass. Note: the bubble size in the van Krevelen diagrams correspond to the relative intensity change after irradiation, whereas the bubble size in the mass diagram corresponds to relative abundance of a mass peak; the red circle highlights the completely photo-degraded, more saturated DOM component during spring time sunlight exposure, whereas the black circle indicates slow photo-degrading, unsaturated and presumably aromatic DOM.

compounds indicated by the changes in absorbance and fluorescence (Figs. 3 and 4).

However, the June bottom water SPE-DOM (and all April samples) showed also another pool of more saturated or aliphatic low oxygen-containing compounds that were photobleached (Fig. 8, red circle and Table 3). These were presumably the precursors for the highly oxidized low molecular weight compounds photochemically produced in all April and the June bottom water samples (Figs. 7 and 8). The DBE and $\mathrm{DBE} / \mathrm{C}$ values are a lot lower and in conjunction with the relatively high $\mathrm{H} / \mathrm{C}$ ratios, are indicative for the much more saturated nature of this component (Table 3).

The lack of these precursor DOM components in the June surface sample and the lack of highly oxidized photochem-

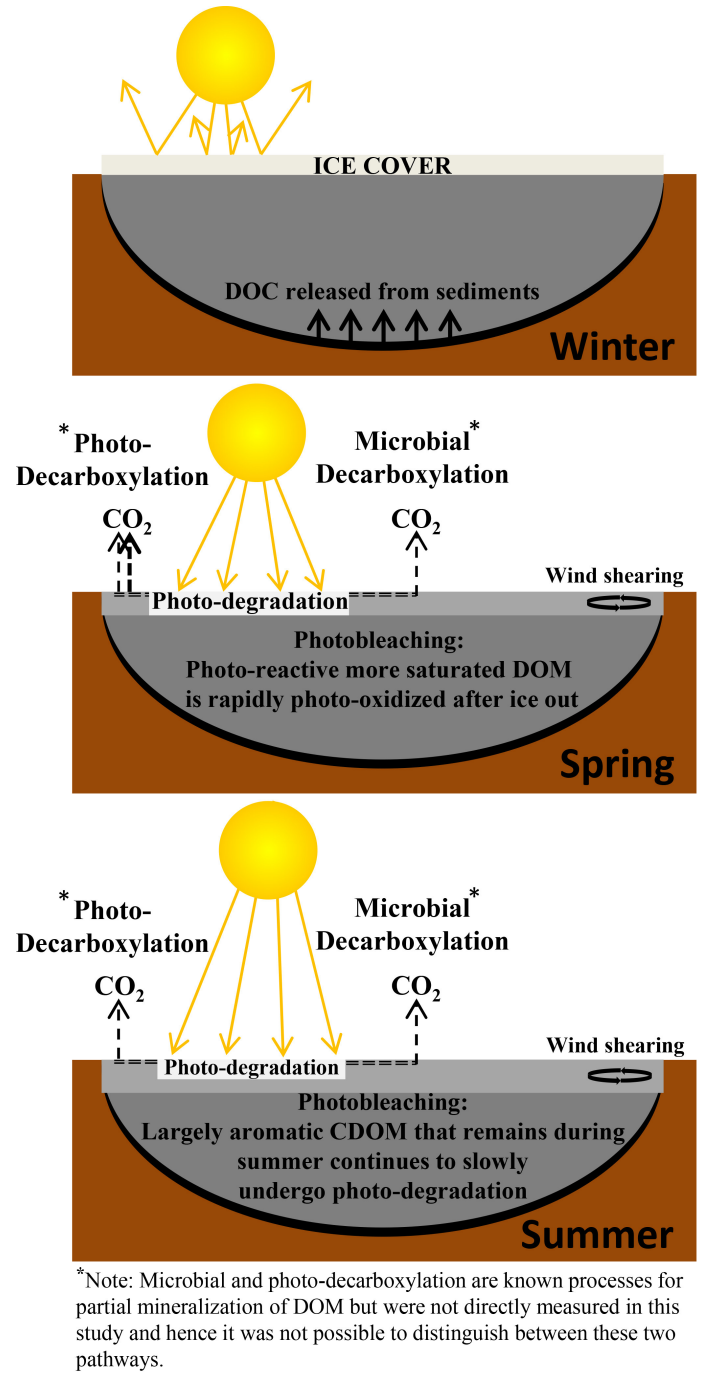

Fig. 9. Conceptual framework of (C)DOM transformation in a boreal lake based on FT-MS analysis of SPE-DOM and photochemical degradation experiments.

ically formed compounds in the same sample and after the light treatment of this sample strongly support this direct link between low $\mathrm{O} / \mathrm{C}$, relatively saturated precursors, and their highly oxidized and lower mass photo products. Despite the photochemically presumably very labile CDOM pool that was completely absent in the June surface sample (Fig. 8, red circle), another CDOM component remained in the summer sample that still showed photochemical reactivity (Fig. 8, black circle). These results suggest the existence of two distinctly different CDOM components, where one is very photo-reactive and is quickly completely degraded/phototransformed even in highly absorbing boreal lake surface waters, and one that is more persistent but still undergoes photochemical transformation. Both components are part of the molecular weight fraction $\geq 300 \mathrm{Da}$ and are responsible 
Table 3. The ten most abundant mass peaks and their associated molecular formulae of each of the two distinctly different pools of (1) aromatic and (2) more saturated/aliphatic photosensitive CDOM components analyzed by FT-MS.

\begin{tabular}{|c|c|c|c|c|c|c|c|c|}
\hline Formulae & $\begin{array}{l}\text { Exact neutral } \\
\text { neutral } \\
\text { mass }\end{array}$ & $\begin{array}{l}\text { Rel. abundance } \\
\text { before } \\
\text { irradiation }\end{array}$ & $\begin{array}{l}\text { Rel. abundance } \\
\text { after } \\
\text { irradiation }\end{array}$ & $\begin{array}{l}\text { Change } \\
(\%)\end{array}$ & $\begin{array}{l}\mathrm{O} / \mathrm{C} \\
\text { ratio }\end{array}$ & $\begin{array}{l}\mathrm{H} / \mathrm{C} \\
\text { ratio }\end{array}$ & $\mathrm{DBE}^{*}$ & $\mathrm{DBE} / \mathrm{C}$ \\
\hline \multicolumn{9}{|c|}{10 highly photo-degraded members of the aromatic CDOM Component } \\
\hline $\mathrm{C} 21 \mathrm{H} 14 \mathrm{O} 5$ & 346.0841 & 4.7 & 1.5 & -37.5 & 0.24 & 0.67 & 15 & 0.71 \\
\hline $\mathrm{C} 20 \mathrm{H} 12 \mathrm{O} 6$ & 348.0634 & 7.5 & 2.0 & -40.4 & 0.30 & 0.60 & 15 & 0.75 \\
\hline $\mathrm{C} 21 \mathrm{H} 14 \mathrm{O} 6$ & 362.079 & 6.8 & 1.9 & -37.7 & 0.29 & 0.67 & 15 & 0.71 \\
\hline $\mathrm{C} 21 \mathrm{H} 12 \mathrm{O} 7$ & 376.0583 & 8.4 & 1.9 & -41.7 & 0.33 & 0.57 & 16 & 0.76 \\
\hline $\mathrm{C} 22 \mathrm{H} 12 \mathrm{O} 7$ & 388.0583 & 7.1 & 1.1 & -46.5 & 0.32 & 0.55 & 17 & 0.77 \\
\hline $\mathrm{C} 22 \mathrm{H} 10 \mathrm{O} 8$ & 402.0376 & 5.5 & 1.0 & -44.4 & 0.36 & 0.45 & 18 & 0.82 \\
\hline $\mathrm{C} 23 \mathrm{H} 14 \mathrm{O} 7$ & 402.074 & 5.0 & 1.1 & -47.2 & 0.30 & 0.61 & 17 & 0.74 \\
\hline C23H12O8 & 416.0532 & 6.1 & 1.2 & -44.2 & 0.35 & 0.52 & 18 & 0.78 \\
\hline C24H14O15 & 542.0333 & 5.2 & 2.2 & -32.7 & 0.63 & 0.58 & 18 & 0.75 \\
\hline $\mathrm{C} 24 \mathrm{H} 14 \mathrm{O} 16$ & 558.0282 & 2.9 & 1.0 & -39.4 & 0.67 & 0.58 & 18 & 0.75 \\
\hline \multicolumn{9}{|c|}{10 highly photo-degraded members of the more aliphatic/saturated CDOM Component } \\
\hline $\mathrm{C} 29 \mathrm{H} 38 \mathrm{O} 8$ & 514.2567 & 3.3 & 1.3 & -46.5 & 0.28 & 1.31 & 11 & 0.38 \\
\hline $\mathrm{C} 30 \mathrm{H} 40 \mathrm{O} 9$ & 544.2672 & 4.2 & 1.7 & -45.7 & 0.30 & 1.33 & 11 & 0.37 \\
\hline $\mathrm{C} 20 \mathrm{H} 26 \mathrm{O} 4$ & 330.1831 & 5.5 & 2.3 & -42.2 & 0.20 & 1.30 & 8 & 0.40 \\
\hline $\mathrm{C} 17 \mathrm{H} 26 \mathrm{O} 4$ & 294.1831 & 4.7 & 2.2 & -38.3 & 0.24 & 1.53 & 5 & 0.29 \\
\hline $\mathrm{C} 26 \mathrm{H} 36 \mathrm{O} 7$ & 460.2461 & 4.3 & 2.0 & -37.7 & 0.27 & 1.38 & 9 & 0.35 \\
\hline $\mathrm{C} 28 \mathrm{H} 42 \mathrm{O} 9$ & 522.2829 & 3.5 & 1.6 & -37.3 & 0.32 & 1.50 & 8 & 0.29 \\
\hline $\mathrm{C} 28 \mathrm{H} 36 \mathrm{O} 8$ & 500.2410 & 4.8 & 2.3 & -37.1 & 0.29 & 1.29 & 11 & 0.39 \\
\hline C28H40O8 & 504.2723 & 5.3 & 2.5 & -36.4 & 0.29 & 1.43 & 9 & 0.32 \\
\hline С $30 \mathrm{H} 38 \mathrm{O} 10$ & 558.2465 & 4.0 & 1.9 & -35.8 & 0.33 & 1.27 & 12 & 0.40 \\
\hline C25H30O7 & 442.1992 & 4.5 & 2.2 & -35.8 & 0.28 & 1.20 & 11 & 0.44 \\
\hline
\end{tabular}

* DBE is the double bond equivalency that represents all carbon-carbon and carbon-oxygen double bonds.

for the photochemical production of lower molecular weight compounds (Fig. 8).

The FT-MS data is consistent with the observations of changes in optical properties and demonstrating that the photochemical reactivity of the June surface SPE-DOM sample was significantly reduced to probably natural photobleaching that had already occurred during the very dry spring in 2011 and the complete loss of a distinct pool of photo reactive aliphatic compounds. In general, these findings are in agreement with previous studies that indicated the decrease in DOM photo-reactivity with irradiation time (Zhang et al., 2006; Moran et al., 2000; Stubbins et al., 2012).

This study suggested that seasonal molecular changes in SPE-DOM can be explained by a synergy between photochemical degradation (including a likely microbial decarboxylation of highly oxidized photo-products) and a possible release of DOM from sediments. Photobleaching can also be considered to play a major role in altering the DOM molecular composition in surface boreal lake waters far beyond the very limited attenuation of light, possibly due to a continuous mixing by wind of the upper water column above the thermocline. This study further suggests a pool of highly photosensitive relatively saturated CDOM that can be quantitatively removed through photobleaching in the surface of highly absorbing boreal lake waters and a CDOM pool of much reduced photobleaching behavior.

Altogether the results based on FT-MS analyses of SPEDOM and laboratory-based photochemical experiments sug- gest periods with extensive photo-mineralization after iceout and lake turnover when DOM from dark parts of the water column (under ice or in the hypolimnion) becomes exposed to light (Fig. 9). The increased photo-reactivity of deep, aphotic waters has also been demonstrated in other environments such as the deep ocean (Mopper et al., 1991). Therefore photo-mineralization may not be uniform over the year but show a distinct seasonal pattern and may be greater over the whole year than inferred from experiments using previously light-exposed DOM.

To summarize the presented results, we developed a conceptual framework (Fig. 9) that emphasizes the observed trends in this study and underlines the importance of seasonal photobleaching differences.

Acknowledgements. Many thanks go to $\mathrm{H}$. Reyier for helping tremendously with the sampling in the lake as well as the technical personnel at the Department of Thematic Studies - Water and Environmental Studies at Linköping University, Sweden. Without the highly advanced analytical instrumentation located at the Helmholtz Center for Environmental Health in Munich, Germany, none of this work would have been possible. This study was financially supported by Linköping University and the Swedish research councils VR and Formas. This is contribution 4764 of the University of Maryland Center for Environmental Science.

Edited by: T. J. Battin 


\section{References}

Anesio, A. M., Graneli, W., Aiken, G. R., Kieber, D. J., and Mopper, K.: Effect of humic substance photodegradation on bacterial growth and respiration in lake water, Appl. Environ. Microb., 71, 6267-6275, doi:10.1128/aem.71.10.6267-6275.2005, 2005.

Bastviken, D., Persson, L., Odham, G., and Tranvik, L.: Degradation of dissolved organic matter in oxic and anoxic lake water, Limnol. Oceanogr., 49, 109-116, 2004.

Bastviken, D., Tranvik, L. J., Downing, J. A., Crill, P. M., and Enrich-Prast, A.: Freshwater Methane Emissions Offset the Continental Carbon Sink, Science, 331, 50-50, doi:10.1126/science.1196808, 2011.

Bertilsson, S. and Allard, B.: Sequential photochemical and microbial degradation of refractory dissolved organic matter in a humic freshwater system, Adv. Limnol., 48, 133-141, 1996.

Bertilsson, S. and Tranvik, L. J.: Photochemically produced carboxylic acids as substrates for freshwater bacterioplankton, Limnol. Oceanogr., 43, 885-895, doi:10.4319/lo.1998.43.5.0885, 1998.

Bracchini, L., Dattilo, A. M., Hull, V., Loiselle, S. A., Martini, S., Rossi, C., Santinelli, C., and Seritti, A.: The biooptical properties of CDOM as descriptor of lake stratification, J. Photochemi. Photobiol. B-Biology, 85, 145-149, doi:10.1016/j.jphotobiol.2006.06.003, 2006.

Cottrell, B. A., Timko, S. A., Devera, L., Robinson, A. K., Gonsior, M., Vizenor, A. E., Simpson, A. J., and Cooper, W. J.: Photochemistry of excited-state species in natural waters: A role for particulate organic matter, Water Res., 47, 5189-5199, doi:10.1016/j.watres.2013.05.059, 2013.

Dittmar, T., Whitehead, K., Minor, E. C., and Koch, B. P.: Tracing terrigenous dissolved organic matter and its photochemical decay in the ocean by using liquid chromatography/mass spectrometry, Mar. Chem., 107, 378-387, 2007.

Dittmar, T., Koch, B., Hertkorn, N., and Kattner, G.: A simple and efficient method for the solid-phase extraction of dissolved organic matter (SPE-DOM) from seawater, Limnol. Oceanogr.Meth., 6, 230-235, 2008.

Downing, J. A. and Duarte, C. M.: Abundance and Size Distribution of Lakes, Ponds and Impoundments, in: Encyclopedia of Inland Waters, edited by: Gene, E. L., Academic Press, Oxford, 469478, 2009.

Einola, E.,Rantakari, M.,Kankaala, P.,Kortelainen, P., Ojala, A.,Pajunen, H.,Makela, S., and Arvola, L.:Carbon pool sand flues in a chain off veboreal lakes: Adry and wet year compari-son, J. Geophys. Res.-Biogeo.,116, 13, doi:10.1029/2010jg001636, 2011.

Gonsior, M., Peake, B. M., Cooper, W. T., Podgorski, D., D'Andrilli, J., and Cooper, W. J.: Photochemically Induced Changes in Dissolved Organic Matter Identified by Ultrahigh Resolution Fourier Transform Ion Cyclotron Resonance Mass Spectrometry, Environ. Sci. Technol., 43, 698-703, doi:10.1021/es8022804, 2009.

Gonsior, M., Zwartjes, M., Cooper, W. J., Song, W., Ishida, K. P., Tseng, L. Y., Jeung, M. K., Rosso, D., Hertkorn, N., and SchmittKopplin, P.: Molecular characterization of effluent organic matter identified by ultrahigh resolution mass spectrometry, Water Res., 45, 2943-2953, doi:10.1016/j.watres.2011.03.016, 2011.

Guillemette, F., and del Giorgio, P. A.: Simultaneous consumption and production of fluorescent dissolved organic matter by lake bacterioplankton, Environ. Microbiol., 14, 1432-1443, doi:10.1111/j.1462-2920.2012.02728.x, 2012.

Helms, J. R., Stubbins, A., Ritchie, J. D., Minor, E. C., Kieber, D. J., and Mopper, K.: Absorption spectral slopes and slope ratios as indicators of molecular weight, source, and photobleaching of chromophoric dissolved organic matter, Limnol. Oceanogr., 53, 955-969, doi:10.4319/lo.2008.53.3.0955, 2008.

Helms, J. R., Stubbins, A., Perdue, E. M., Green, N. W., Chen, H., and Mopper, K.: Photochemical bleaching of oceanic dissolved organic matter and its effect on absorption spectral slope and fluorescence, Mar. Chem., 155, 81-91, doi:10.1016/j.marchem.2013.05.015, 2013.

Hsu, C. S., Qian, K., and Chen, Y. C.: An innovative approach to data analysis in hydrocarbon characterization by on-line liquid chromatography-mass spectrometry, Anal. Chim. Acta, 264, 7989, doi:10.1016/0003-2670(92)85299-L, 1992.

Janot, N., Reiller, P. E., Korshin, G. V., and Benedetti, M. F.: Using Spectrophotometric Titrations To Characterize Humic Acid Reactivity at Environmental Concentrations, Environ. Sci. Technol., 44, 6782-6788, doi:10.1021/es1012142, 2010.

Kendrick, E.: A mass scale based on $\mathrm{CH} 2=140000$ for high resolution mass spectrometry of organic compounds, Anal. Chem., 35, 2146, 1963.

Kim, S., Kramer, R. W., and Hatcher, P. G.: Graphical Method for Analysis of Ultrahigh-Resolution Broadband Mass Spectra of Natural Organic Matter, the Van Krevelen Diagram, Anal. Chem., 75, 5336-5344, 2003.

Kothawala, D. N., von Wachenfeldt, E., Koehler, B., and Tranvik, L. J.: Selective loss and preservation of lake water dissolved organic matter fluorescence during long-term dark incubations, Sci. Total Environ., 433, 238-246, doi:10.1016/j.scitotenv.2012.06.029, 2012.

Lou, T. and Xie, H. X.: Photochemical alteration of the molecular weight of dissolved organic matter, Chemosphere, 65, 23332342, doi:10.1016/j.chemosphere.2006.05.001, 2006.

Mopper, K., Zhou, X. L., Kieber, R. J., Kieber, D. J., Sikorski, R. J., and Jones, R. D.: Photochemical degradation of dissolved organic carbon and its impact on the oceanic carbon cycle, Nature, 353, 60-62, doi:10.1038/353060a0, 1991.

Moran, M. A. and Zepp, R. G.: Role of photoreactions in the formation of biologically labile compounds from dissolved organic matter, Limnol. Oceanogr., 42, 1307-1316, 1997.

Moran, M. A., Sheldon, Jr., W. M., and Zepp, R. G.: Carbon Loss and Optical Property Changes during Long-Term Photochemical and Biological Degradation of Estuarine Dissolved Organic Matter, Limnol. Oceanogr., 45, 1254-1264, 2000.

Pace, M. L., Reche, I., Cole, J. J., Fernandez-Barbero, A., Mazuecos, I. P., and Prairie, Y. T.: $\mathrm{pH}$ change induces shifts in the size and light absorption of dissolved organic matter, Biogeochemistry, 108, 109-118, doi:10.1007/s10533-011-9576-0, 2012.

Phelps, T. J. and Zeikus, J. G.: Influence of $\mathrm{pH}$ on Terminal Carbon Metabolism in anoxic Sediments from a midly acidic Lake, Appl. Environ. Microb., 48, 1088-1095, 1984.

Reche, I., Pace, M. L., and Cole, J. J.: Modeled effects of dissolved organic carbon and solar spectra on photobleaching in lake ecosystems, Ecosystems, 3, 419-432, doi:10.1007/s100210000038, 2000. 
Schmitt-Kopplin, P. and Hertkorn, N.: Ultrahigh resolution mass spectrometry, Anal. Bioanal. Chem., 389, 1309-1310, doi:10.1007/s00216-007-1589-0, 2007.

Shakeri Yekta, S., Gonsior, M., Schmitt-Kopplin, P., and Svensson, B. H.: Characterization of Dissolved Organic Matter in Full Scale Continuous Stirred Tank Biogas Reactors Using Ultrahigh Resolution Mass Spectrometry: A Qualitative Overview, Environ. Sci. Technol., 46, 12711-12719, doi:10.1021/es3024447, 2012.

Skoog, A. C. and Arias-Esquivel, V. A.: The effect of induced anoxia and reoxygenation on benthic fluxes of organic carbon, phosphate, iron, and manganese, Sci. Total Environ., 407, 60856092, doi:10.1016/j.scitotenv.2009.08.030, 2009.

Sobek, S., DelSontro, T., Wongfun, N., and Wehrli, B.: Extreme organic carbon burial fuels intense methane bubbling in a temperate reservoir, Geophys. Res. Lett., 39, doi:10.1029/2011g1050144, 2012.

Stenson, A. C., Marshall, A. G., and Cooper, W. T.: Exact Masses and Chemical Formulas of Individual Suwannee River Fulvic Acids from Ultrahigh Resolution Electrospray Ionization Fourier Transform Ion Cyclotron Resonance Mass Spectra, Anal. Chem., 75, 1275-1284, 2003.

Stubbins, A., Spencer, R. G. M., Chen, H., Hatcher, P. G., Mopper, K., Hernes, P. J., Mwamba, V. L., Mangangu, A. M., Wabakanghanzi, J. N., and Six, J.: Illuminated darkness: molecular signatures of Congo River dissolved organic matter and its photochemical alteration as revealed by ultrahigh precision mass spectrometry, Limnol. Oceanogr., 55, 1467-1477, doi:10.4319/lo.2010.55.4.1467, 2010.

Stubbins, A., Niggemann, J., and Dittmar, T.: Photo-lability of deep ocean dissolved black carbon, Biogeosciences, 9, 1661-1670, doi:10.5194/bg-9-1661-2012, 2012.

Thomson, J., Parkinson, A., and Roddick, F. A.: Depolymerization of chromophoric natural organic matter, Environ. Sci. Technol., 38, 3360-3369, doi:10.1021/es049604j, 2004.

Tranvik, L. J. and Bertilsson, S.: Contrasting effects of solar UV radiation on dissolved organic sources for bacterial growth, Ecol. Lett., 4, 458-463, doi:10.1046/j.1461-0248.2001.00245.x, 2001.
Tranvik, L. J., Downing, J. A., Cotner, J. B., Loiselle, S. A., Striegl, R. G., Ballatore, T. J., Dillon, P., Finlay, K., Fortino, K., Knoll, L. B., Kortelainen, P. L., Kutser, T., Larsen, S., Laurion, I., Leech, D. M., McCallister, S. L., McKnight, D. M., Melack, J. M., Overholt, E., Porter, J. A., Prairie, Y., Renwick, W. H., Roland, F., Sherman, B. S., Schindler, D. W., Sobek, S., Tremblay, A., Vanni, M. J., Verschoor, A. M., von Wachenfeldt, E., and Weyhenmeyer, G. A.: Lakes and reservoirs as regulators of carbon cycling and climate, Limnol. Oceanogr., 54, 2298-2314, doi:10.4319/lo.2009.54.6_part_2.2298, 2009.

von Wachenfeldt, E. and Tranvik, L. J.: Sedimentation in boreal lakes - The role of flocculation of allochthonous dissolved organic matter in the water column, Ecosystems, 11, 803-814, doi:10.1007/s10021-008-9162-z, 2008.

Wu, Z. G., Rodgers, R. P., and Marshall, A. G.: Two- and three-dimensional van Krevelen diagrams: A graphical analysis complementary to the Kendrick mass plot for sorting elemental compositions of complex organic mixtures based on ultrahigh-resolution broadband Fourier transform ion cyclotron resonance mass measurements, Anal. Chem., 76, 2511-2516, doi:10.1021/ac0355449, 2004.

Xie, H. X., Zafiriou, O. C., Cai, W. J., Zepp, R. G., and Wang, Y. C.: Photooxidation and its effects on the carboxyl content of dissolved organic matter in two coastal rivers in the Southeastern United States, Environ. Sci. Technol., 38, 4113-4119, doi:10.1021/es035407t, 2004.

$\mathrm{Xu}, \mathrm{M}$. S. and Wan, P.: Efficient photodecarboxylation of aroylsubstituted phenylacetic acids in aqueous solution: a general photochemical reaction, Chem. Commun., 2147-2148, doi:10.1039/b006724p, 2000.

Zepp, R. G., Sheldon, W. M., and Moran, M. A.: Dissolved organic fluorophores in southeastern US coastal waters: correction method for eliminating Rayleigh and Raman scattering peaks in excitation-emission matrices, Mar. Chem., 89, 15-36, 2004.

Zhang, Y., Xie, H. and Chen, G.: Factors affecting the efficiency of carbon monoxide photoproduction in the St. Lawrence Estuarine system (Canada), Environ. Sci. Technol., 40, 7771-7777, doi:10.1021/es0615268, 2006. 